\title{
THE ITEP-TWAC INJECTION AND EXTRACTION KICKER
}

\author{
V. Krasnopolsky, S. Krylov, G. Mamaev", S. Mamaev, S. Poutchkov, \\ I. Tenyakov, V. Fedorov, MRTI RAS, Moscow \\ A. Sidorov, JINR, Dubna \\ N. Alekseev, ITEP, Moscow
}

\section{Abstract}

The system multi-turn injection and fast extraction for installation ITEP-TWAC is developing in MRTI RAS. In this paper one kicker in injection ring and one extraction kicker in storage ring are described. In both kickers rise time of magnetic field is not more $300 \mathrm{~ns}$, and platen duration 300-500 ns. The total length of the injection kicker is $1.8 \mathrm{~m}$, aperture is $0.1 \times 0.1 \mathrm{~m}$ and kicker strength is $0.16 \mathrm{~T} \cdot \mathrm{m}$. The total length of the extraction kicker is $1.5 \mathrm{~m}$, aperture is $0.09 \times 0.09 \mathrm{~m}$ and kicker strength is $0.14 \mathrm{~T} \cdot \mathrm{m}$. Both kickers are situated outside vacuum chamber and consisted of number uniform sections $0.3 \mathrm{~m}$ length. In each section ferrite magnet, pulse former line, matched resistor $2.5 \mathrm{Ohm}$ and $50 \mathrm{kV}$ ceramic metal thyratron with grounded grid are used. Pulse current in each magnet achieves 7-8 $\mathrm{kA}$ in order to magnetic field not more $0.1 \mathrm{~T}$. In each former line concentration capacitors and inductance in order to storage energy and pulse correction are used. The compact pulse power supply system in each section gives the possibility connection with magnet short feed buses without low-impedance $2.5 \mathrm{Ohm}$ cable.

\section{GENERAL DESIGN}

The kicker of the injection ring (kicker 1) and the kicker of the storage ring (kicker 2) are parts of installation ITEP-TWAC [1]. A performance specification for the kickers is given in table 1 and table 2 .

Table 1: The specification of the kicker 1.

$\begin{array}{ll}\text { Magnet total length } & 1.812 \mathrm{~m} \\ \text { Magnetic field } & 0,0883 \mathrm{~T} \\ \text { Rise time (1-95\%) } & 300 \mathrm{~ns} \\ \text { Flat top } & (300-500) \mathrm{ns} \\ \text { Fall time } & \text { Unlimited } \\ \text { Flat top tolerance } & \pm 5 \% \\ \text { Repetition period } & 1 \mathrm{~s} \\ \text { Beam aperture in magnet } & 80 \mathrm{~mm} \text {-diam. } \\ \text { Field uniformity in half-aperture } & \pm 3 \%\end{array}$

*E-Mail: mamaev_g@mail.sitek.ru
Table 2: The specification of the kicker 2.

$\begin{array}{ll}\text { Magnet total length } & 1,51 \mathrm{~m} \\ \text { Magnetic field } & 0,0947 \mathrm{~T} \\ \text { Rise time (1-95\%) } & 300 \mathrm{~ns} \\ \text { Flat top } & (300-500) \mathrm{ns} \\ \text { Fall time } & \text { Unlimited } \\ \text { Flat top tolerance } & \pm 5 \% \\ \text { Repetition period: } & 1 \mathrm{~s} \\ \text { Beam aperture in magnet } & 70 \mathrm{~mm} \text { - diam. } \\ \text { Field uniformity in half-aperture } & \pm 3 \%\end{array}$

Series parameters each kicker is near parameters kicker for installation "Mirabel" [2]. For this reason each magnet consist of sections like "Mirabel" magnets and each section is connected to self-contained pulse supply unit. Kicker 1 consist of six sections, kicker 2 consist of five sections. The ceramic beam tube is used in kickers because the vacuum in the installation ITEP-TWAC is very high $\left(10^{-10}-10^{-13}\right.$ torr $)$.

\section{MAGNETS}

The cross section of magnets is shown in Fig. 1. Kicker 1: $\quad \mathrm{h}=100 \mathrm{~mm}$; $\mathrm{s}=100 \mathrm{~mm}, \mathrm{D}=\mathbf{8 0} \mathrm{mm}$. Kicker2: $\mathrm{h}=90 \mathrm{~mm} ; \mathrm{s}=90 \mathrm{~mm}, \mathrm{D}=70 \mathrm{~mm}$.

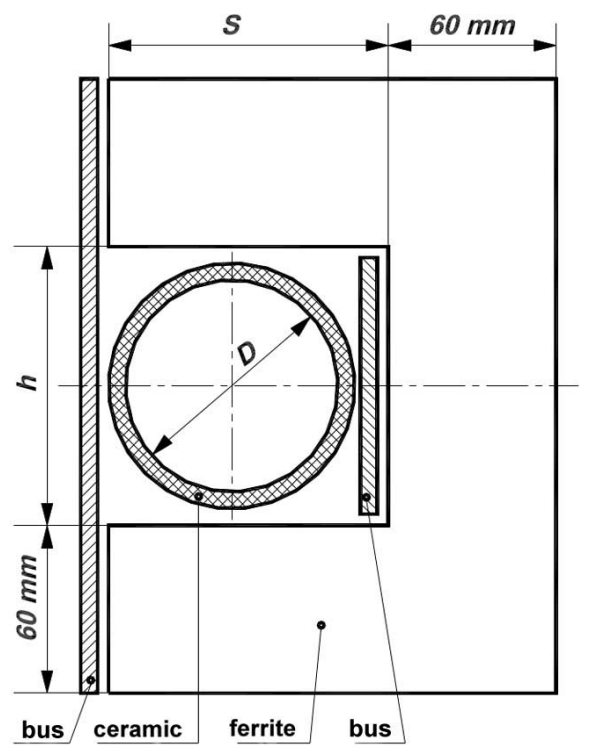

Figure 1: Cross-section of magnets. 
The length of each section of each magnet is equal to $300 \mathrm{~mm}$, and ratio $\mathrm{h} / \mathrm{s}$ of each section is equal to 1 . In the results the inductance of each section is equal to $400 \mathrm{nH}$. The magnetic circuit consist of ferrite $600 \mathrm{NN}$. The thickness of ferrite plate is $20 \mathrm{~mm}$. Epoxy compound is used for gluing. The feed buses are manufactured from aluminium. For target magnetic field we have to receive the current near to $8 \mathrm{kA}$ in feed buses. The ferrite and feed buses are situated in air and in the result the aircooling is possible.

(Look right for continue).

\section{PULSE SUPPLY UNIT}

The rise time of pulse 300 ns gives the possibility to use in forming line concentrated capacitors and inductances [3]. The commutator for current $8 \mathrm{kA}$ is the main problem in our case. The thyratron TGI1-2500/50 is used. It works at voltage $40-50 \mathrm{kV}$ and connected on the circuit with a grounded grid $[4,5]$. In this circuit the main current of a load going through the gap anode-grid and the gap grid-cathode is used only for initial pulse. In this case the oxide-coated cathode is not destroy. Each of magnet section connected to self-contained pulse supply unit, which electric circuit is shown in Fig. 2.

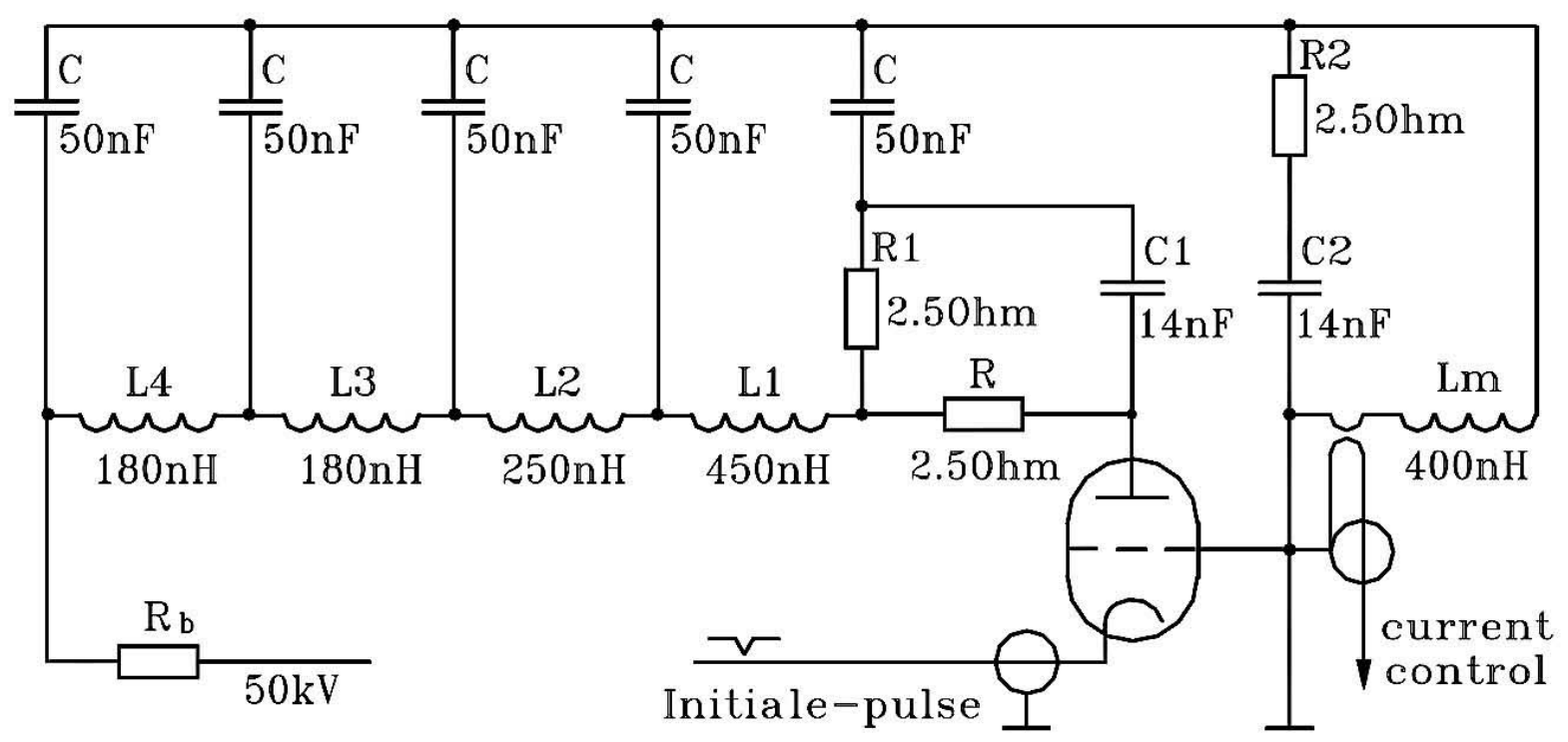

Figure 2: Electric circuit pulse supply unit in connection of the magnet.

Own inductances of capacitors and buses are not shown in Fig. 2, but were considered in the pulse current calculation. Own inductance of a magnet Lm fulfils functions of inductance of the first cell. Common number of cells is equal to five. The small number of cells has required for optimization of the form of pulse to use forming line with various inductances L1-L4 in cells. For correction of front of pulse two additional cells R1 C1 and $\mathrm{R} 2 \mathrm{C} 2$ were added also. The matched resistor $\mathrm{R}=2,5$ $\mathrm{Ohm}$ is connected between anode of the thyratron and output of line. The small value of resistor $\mathrm{R}=2.5 \mathrm{Ohm}$ could make difficulty for connection of a forming line with magnet by a long cable with a low impedance $Z=$ $2,5 \mathrm{Ohm}$. Taking into account difficulties of using of such cable we decided to place each unit near to appropriate section of the magnet and to use for connection the pair of short buses. Buses are connected to the grounded grid of the thyratron and to another output of line. Their inductance is not more than $180 \mathrm{nH}$. Due to this the high voltage on buses is absent during charging a line and on a flat top when $\mathrm{U}=\mathrm{Lm} \cdot \mathrm{dI} / \mathrm{dt} \sim 0$. The voltage arises only during the rise time and the fall time of pulse and is not more than $25 \mathrm{kV}$. It simplifies the high-voltage insulation of buses and ferrite in magnet located on an air.

During development one or two type ceramic and oil capacitors were tested. As a result oil capacitors IK1000.05 were used in cells of line $\mathrm{C}$ and ceramic capacitors KVI-3 were used in cells R1C1, R2C2.

The experimental model of the unit kickerl was manufactured as a result of development. It consists of the pulse supply unit and the section of magnet. The general view of the model is shown in Fig. 3.

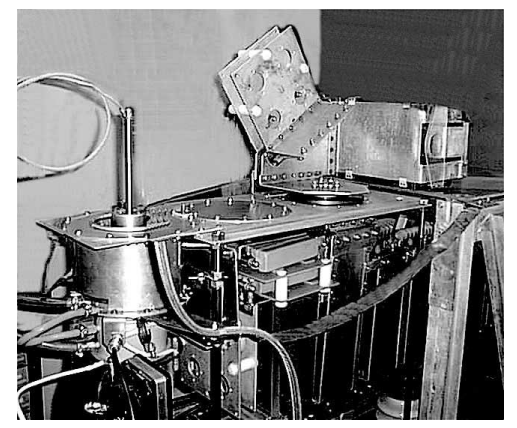

Figure 3: Experimental model of the unit kicker1. 


\section{EXPERIMENTAL RESULTS AND FUTURE DEVELOPMENTS}

On experimental model electrical durability, form of pulse of a current in buses of a magnet and pulse of a magnetic field in a working clearance and also uniformity of a magnetic field were investigated. Single break-down in air on constant charge voltage were observed only $35 \mathrm{kV}$ up, nevertheless they have not hindered to lift charge voltage up to $47 \mathrm{kV}$ and to achieve the calculated current $8 \mathrm{kA}$. There were no breakdowns in insulation of buses of a magnet during pulse voltage. The form of pulse of a current in buses of a magnet and pulse of a magnetic field in clearance was further defined. The measurements were carried out by two types of monitors and have shown satisfactory coincidence with calculated form of pulse.

The outcome is shown in Fig. 4.

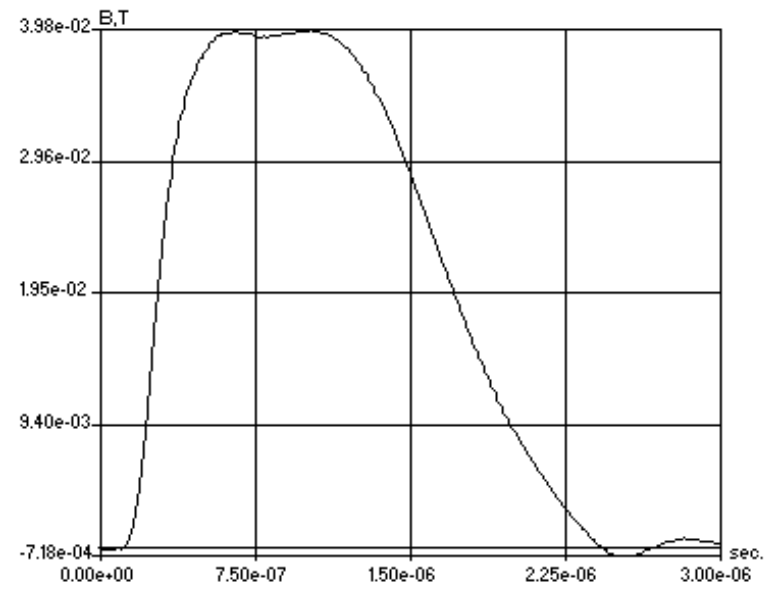

Figure 4: Magnetic field pulse in the median plane (charge voltage $\mathrm{U}=20 \mathrm{kV}$ ).

The necessary charge voltage was defined as the result of measurements. For kicker 1 it is equal $48 \mathrm{kV}$, for kicker 2 it is equal $46 \mathrm{kV}$. The oil insulation in a power supply unit was decided to use for the guaranteed electrical reliability. This oil insulation is used for all parts of unit, where constant charge voltage is, including a thyratron. The construction of a power supply unit with oil insulation is developed.

Preliminary measurements the uniformity of a magnetic field in the median plane were made also. At the distance $15 \mathrm{~mm}$ from the center of ceramic tube the uniformity is equal $(2.0-2.5) \%$.

The test of the power supply unit with oil insulation and the measurement uniformity of a magnetic field in full aperture are planed for nearest future.

\section{ACKNOWLEDGMENTS}

We sincerely thank O. Kurnaev for valuable consultations and advise.

\section{REFERENCES}

[1] N. Alekseev, D Koshkarev, B. Sharkov et. al., "Modernization of the Accelerator-storage Facility in ITEP-project ITEP-TWAC, 15* Russian Charged Particle Accelerator Workshop, v.2, p. 319., Protvino, 1996

[2] A. Aseev, A. Afonin, A. Drogdin et. al., "Proton Quick Ejection from $70 \mathrm{GeV}$ Accelerator for Liquid Hydrogen Chamber "Mirabel", Proceedings 3d Charged Particle Accelerator Workshop, v.2, p. 160, M., "Science", 1978

[3] Y. Vahrushin, A. Anackiy, "Line Induction Accelerators", M. Atomisdat, 1978, p. 78-82.

[4] Ceramic Metal grid Thyratrons, EGG Electro-Optical Division, Data sheet H5003B-1, 1974, p.1-3, USA

[5] A. Belaev et. al., "Investigations of the Start and Commutation Thyratrons TGI1-2500/50, JINR, 9-10313, Dubna, 1976 